\title{
Direito ao trabalho em tempos de pandemia
}

https://doi.org/10.21814/uminho.ed.25.5

\section{Teresa Coelho Moreira}

Teresa Coelho Moreira (ORCID: 0000-0003-1638-2800) é Professora Auxiliar da Escola de Direito da Universidade do Minho e investigadora do JusGov - Centro de Investigação em Justiça e Governação, no qual é coordenadora do Grupo de Investigação em Direitos Humanos. É Vice-Presidente da Direção da APODIT - Associação Portuguesa de Direito do Trabalho. 
$1 \mathrm{O}$ mundo atualmente vive tempos únicos, de grande incerteza, atravessando-se períodos bastantes conturbados da história mundial. Assistimos a grandes mudanças a vários níveis que originaram o confinamento, a quarentena, uma distância social, uma mudança de comportamentos e uma enorme contração da atividade económica. Ninguém sabe o dia de amanhã e como a sociedade vai ser no pós-vírus, pois este vírus, invisível a olho nu, conseguiu fazer-se mostrar de uma forma sem precedentes. Talvez o mais avisado nesta altura seja não planear, não fazer planos a longo prazo ${ }^{1}$. Contudo, isso não significa que não se tomem medidas para tentar diminuir os efeitos deste vírus, por forma a salvar vidas e empregos pois, mais uma vez, ficou bem patente a centralidade do trabalho humano na vida das pessoas. $\mathrm{O}$ trabalho não significa apenas a principal fonte de rendimento para a maior parte das pessoas no mundo. O trabalho é também, para muitos, uma forma de estar em sociedade, de dignidade e até de identidade, sendo a forma de participação na sociedade para muitos. O trabalho não deve ser visto apenas como uma forma de remuneração económica, mas também como uma forma de estar em sociedade. E a carência de emprego ou a sua existência precária minam as possibilidades de integração, podendo romper-se a coesão social e criarem-se situações de exclusão, fazendo perigar a estabilidade social da sociedade.

Por isso, o desemprego tem inúmeros custos económicos, sociais, psicológicos que justificam a afirmação de Viviane Forrester ${ }^{2}$ quando diz que "para lá da exploração do homem há algo pior: a ausência de qualquer exploração”.

2 Atendendo a esta situação os países tiveram de adotar medidas urgentes para tentar conter a pandemia e Portugal não foi exceção, tendo aprovado várias medidas em diversos setores e declarado o estado de emergência no dia 18 de março através do Decreto do Presidente da República no 14-A/2020. Contudo, antes mesmo desta declaração, várias medidas foram implementadas, sendo que apenas nos iremos debruçar sobre algumas com relevância para o Direito do trabalho.

\footnotetext{
1 Como escreve João Leal Amado, "Emergência, calamidade e despedimento: o empoderamento da ACT", in $R M P$, no prelo, "Veremos o que o futuro nos reserva, com a conviç̧ão de que, nisto como em tudo, os planos e as previsóes de pouco servem".
}

2 (1997). O Horror Económico, trad., Terramar, p.18. 
Não podemos deixar, contudo, de ter em atenção que esta legislação é uma espécie de work in progress. Assistimos a momentos de incerteza, de passos num terreno desconhecido e, por isso, necessariamente, a legislação também traduz esse campo. É uma legislação um pouco mutante e até pouco convencional nalgumas matérias, porque a situação também não é estanque, nem convencional. É uma situação que muda e várias dúvidas surgem depois da legislação já ter sido aprovada e, por isso, é necessário completá-la e melhorá-la. Claramente não é a melhor técnica legislativa. Todos teríamos críticas certeiras como é óbvio a este processo legislativo, mas, em tempos de pandemia, em tempos de incerteza, não conseguimos vislumbrar outro caminho que não seja este de navegar junto à costa e tentando antecipar algumas situações.

3 Portugal teve os primeiros casos de COVID no dia 2 de março e pouco tempo depois começaram a adotar-se inúmeras medidas para evitar o crescimento exponencial dos casos e a rutura do sistema nacional de saúde. Assim, há que ver que as primeiras medidas tomadas foram exatamente no sentido de tentar evitar grandes aglomerados de pessoas e promover o distanciamento social. Há que dizer, contudo, que mesmo antes da adoção destas medidas, existiu uma diminuição voluntária de pessoas em determinados locais, de reunióes, de eventos e mesmo escolas que encerraram antes da decisão oficial tomada pelo Governo dia 12 de março e com produção de efeitos a partir do dia 16 de março. Pode ver-se, assim, que passados 10 dias dos primeiros casos, já se tinham adotado medidas para promover o isolamento social.

Obviamente que todas estas medidas têm um impacto enorme no emprego, no trabalho e na economia do país. Atendendo a esta situação o Governo aprovou um conjunto de medidas temporárias e simplificadas visando ajudar as empresas a suportar o impacto económico desta pandemia. Estas medidas consistem, inter alia, em reduzir ou aliviar os compromissos perante a banca, o fisco e a segurança social e os trabalhadores, com vista a manter o emprego e a proporcionar meios financeiros para continuar a pagar aos fornecedores e aos trabalhadores que se mantenham em funções. 
4 Uma das primeiras medidas que foi adotada como uma forma de reforçar o isolamento social foi a adoção generalizada do teletrabalho nas atividades que o permitam. O teletrabalho encontra-se regulado no art. 165을 do CT - "Considera-se teletrabalho a prestação laboral realizada com subordinação jurídica, habitualmente fora da empresa e através do recurso a tecnologias de informação e de comunicação”.

Em princípio, o teletrabalho funda-se, necessariamente, no consenso de ambos os sujeitos. Assim, o empregador não pode converter uma relação laboral típica numa relação de teletrabalho. E o trabalhador também não goza de tal direito de conversão unilateral. Há, contudo, desvios a esta regra da necessidade de acordo, verificadas que sejam as condições previstas no no 1 do art. 195o do CT, o trabalhador que tenha sido vítima de violência doméstica terá direito a passar a exercer a atividade em regime de teletrabalho, quando este seja compatível com a atividade desempenhada, nos termos do no 2 do art. 166으, ou nos termos do art. 166으, no 3, o trabalhador com filho com idade até 3 anos tem direito a exercer a atividade em regime de teletrabalho, quando este seja compatível com a atividade desempenhada e o empregador disponha de recursos e meios para o efeito, não podendo este, nos termos do no 4 , opor-se ao correspondente pedido do trabalhador.

Contudo, perante o cenário de pandemia que vivemos, esta necessidade de acordo mudou e alterou-se. Numa primeira fase, através do art. 29o, no 1 do do DL no 10-A/2020, de 13 de março, estabeleceu-se que "Durante a vigência do presente decreto-lei, o regime de prestação subordinada de teletrabalho pode ser determinado unilateralmente pelo empregador ou requerido pelo trabalhador, sem necessidade de acordo das partes, desde que compatível com as funçốes exercidas”. O no 2 do art. 29o ressalvava, contudo, os trabalhadores abrangidos pelo disposto no art. 10o do diploma, isto é, aqueles que desenvolvessem atividades em serviços essenciais como, por exemplo, os profissionais de saúde, das forças e serviços de segurança e de socorro, incluindo os bombeiros voluntários, e das forças armadas, os trabalhadores dos serviços públicos essenciais ou de gestão e manutenção de infraestruturas essenciais, aos quais a regra do no 1 não se aplicava.

Segundo o estabelecido neste artigo, inserido num contexto de uma grave situação epidemiológica que impóe um elevado grau de isolamento social, como forma de 
prevenir o contágio, o recurso ao teletrabalho na modalidade de teletrabalho no domicílio surge como uma alternativa adequada, pelo que o legislador resolveu prescindir da necessidade de consenso das partes para que o trabalho passasse a ser efetuado em regime de teletrabalho. Ao abrigo do primeiro preceito, o empregador poderia ordenar que o trabalhador passasse a prestar a sua atividade em regime de teletrabalho, assim como o próprio trabalhador poderia requerer a passagem para tal situação, sem necessidade de acordo da contraparte. Tudo isto, claro, desde que as funções em causa assim o permitissem, pois existem atividades que, pela sua própria natureza, não podem ser efetuadas à distância e, mesmo assim, sem esquecer a ressalva dos serviços essenciais, feita pelo ํo 2 do art. 29ํㅗ․

Numa segunda fase, após o Decreto que estabeleceu o estado de emergência, o Decreto do Presidente da República no 14-A/2020, de 18 de março, o Governo aprovou um diploma estabelecendo os termos das medidas a implementar durante a vigência do estado de emergência, através do Decreto no 2-A/2020, de 20 de março, no qual o teletrabalho não foi esquecido pois, de acordo com o art. 6o decretou-se, sem ambiguidades, que "é obrigatória a adoção do regime de teletrabalho, independentemente do vínculo laboral, sempre que as funçôes em causa o permitam”. Ou seja, mais do que uma opção, mais do que um direito que pode ser invocado perante a contraparte, o recurso ao teletrabalho, quando as funçóes em causa o permitam, volveu-se numa obrigação para ambos os sujeitos da relação laboral, enquanto vigorar o estado de emergência ${ }^{4}$.

Norma reafirmada, com a mesma redação, nos diplomas subsequentes, passando a ser o art. 8o do Decreto no 2-B/2020, de 2 de abril, e do Decreto no 2-C/2020, de 17 de abril. O regime em causa manteve-se no art. 4o do diploma que declarou a situação de calamidade em todo o território nacional através da Resolução do Conselho de Ministros no 33-A/2020, de 30 de abril.

\footnotetext{
3 Ver, para maiores desenvolvimentos, João Leal Amado, O teletrabalho: do Código à COVID-19, in https:// observatorio.almedina.net/index.php/2020/03/25/o-teletrabalho-do-codigo-a-COVID-19/.

4 Cf. Teresa Coelho Moreira, Portuguese Labour Law in times of COVID 19: some aspects, in https://officialblogofunio.com/2020/04/06/portuguese-labour-law-in-times-of-COVID19-some-aspects/.
} 
Contudo, alterou-se a redação no DL no 22/2020, de 16 de maio e passou a estabelecer-se no art. 29, no 1 , novamente, a possibilidade de ser uma opção, já que se consagrou que "Durante a vigência do presente decreto-lei, o regime de prestação subordinada de teletrabalho pode ser determinado unilateralmente pelo empregador ou requerida pelo trabalhador, sem necessidade de acordo das partes, desde que compatível com as funções exercidas".

Mais recentemente, na Resolução do Conselho de Ministros no 40/2020, de 29 de maio, o art. 4º, remeteu a manutenção do teletrabalho para o regime geral do CT, ou seja, a regra volta a ser a do acordo entre o empregador e o trabalhador, a não ser nos casos abrangidos pelo no 2 deste artigo onde continua a ser obrigatório mas sujeito a determinados requisitos 5 .

De qualquer das formas uma coisa é certa. Como alguém escreveu, uma das coisas que a COVID-19 parece ter provado aos trabalhadores consiste em que "the job you were told couldn't be done remotely can be done remotely"'.

5 Para evitar o contágio, determinou-se, ainda, que o isolamento profilático dos trabalhadores, subordinados e independentes, é equiparado a doença. No entanto, recebem um subsídio superior ao que se paga em caso de doença e que equivale a 100\% da retribuição, nos primeiros 14 dias. Também se considera falta justificada a que se deva à necessidade de acompanhar neto ou filho sujeito a isolamento profilático ou, ainda, as faltas dadas para acompanhar filhos ou outros menores dependentes até 12 anos (ou, independentemente da idade, com deficiência ou doença crónica) cujas atividades letivas tenham sido suspensas, sendo que os trabalhadores nestas circunstâncias recebem um apoio do Estado, desde que não tenham outro cônjuge, ou companheiro em regime de teletrabalho.

\footnotetext{
5 É interessante notar que no Programa de Estabilização Económica e Social, aprovado pela Resolução do Conselho de Ministros no 41/2020, de 6 de junho, no ponto 2.6.1., "O Governo pretende, até ao final da legislatura, ter em teletrabalho pelo menos $25 \%$ dos trabalhadores de entre o universo daqueles que exercem funções compatíveis com esta modalidade de trabalho", assim como visa a criação de apoios ao teletrabalho no interior do país no ponto 2.6.2.

6 João Leal Amado, última op. cit.
} 
6 Outra das medidas está relacionada com a criação de um sistema simplificado de lay off, isto é, de redução ou suspensão da atividade económica.

Relativamente aos efeitos da suspensão do contrato de trabalho, o art. 295o do CT determina que durante a suspensão mantêm-se os direitos, deveres e garantias das partes que não pressuponham a efetiva prestação de trabalho; o tempo de suspensão conta-se para efeitos de antiguidade; e a suspensão não tem efeitos no decurso do prazo de caducidade, nem obsta a que qualquer das partes faça cessar o contrato nos termos gerais. Terminado o período de suspensão, são restabelecidos os direitos, deveres e garantias das partes decorrentes da efetiva prestação de trabalho.

Contudo, o CT estabelece várias modalidades de suspensão e só uma releva para este efeito: a suspensão por facto respeitante ao empregador como o caso da suspensão coletiva, em caso de encerramento temporário do estabelecimento.

Nos termos do art. 298o, no 1, do CT, o empregador poderá suspender os contratos de trabalho "por motivos de mercado, estruturais ou tecnológicos, catástrofes ou outras ocorrências que tenham afetado gravemente a atividade normal da empresa, desde que tal medida seja indispensável para assegurar a viabilidade da empresa e a manutenção dos postos de trabalho". Quando tal suceda, o empregador deverá comunicar a sua intenção de suspender a prestação do trabalho à estrutura representativa dos trabalhadores ou, na sua falta, a cada trabalhador a abranger, disponibilizando, para consulta, os documentos em que suporta a alegação de situação de crise empresarial, designadamente de natureza contabilística e financeira, nos termos do art. 2999, após o que se abre uma fase de informações e de negociação entre as partes, com vista à obtenção de um acordo sobre a matéria - art. 300․ A suspensão do contrato deve ter uma duração previamente definida, não superior a seis meses, sendo que o prazo de suspensão pode ser de um ano, em caso de catástrofe ou outra ocorrência que tenha afetado gravemente a atividade normal da empresa, prazo que poderá ser prorrogado por mais seis meses, mediante decisão escrita e fundamentada do empregador de acordo com o art. 301‥

Quanto aos direitos e deveres das partes durante o período de suspensão, a lei estabelece que o trabalhador terá direito "a auferir mensalmente um montante mínimo 
igual a dois terços da sua retribuição normal ilíquida, ou o valor da retribuição mínima mensal garantida correspondente ao seu período normal de trabalho, consoante o que for mais elevado" nos termos do art. 305ㅇ, no 1, al. a), assim garantindo-se ao trabalhador um rendimento equivalente à retribuição mínima garantida ou a $2 / 3$ da remuneração que ele auferia normalmente, conforme o que for mais alto, bem como a exercer outra atividade remunerada consoante o previsto no art. 305으, no 1, al. c), tendo como limite máximo o triplo da retribuição mínima mensal garantida - art. 305, no 3. Assim, verdadeiramente, há um limite mínimo, representado pelo valor do salário mínimo nacional - 635€, e um limite máximo, correspondente ao triplo do salário mínimo nacional - o que perfaz $1905 €$. Convém ver, contudo, e apesar do que está previsto na al. a) do no 1 do art. 305o do CT, o trabalhador só receberá $2 / 3$ da sua remuneração normal, caso esses $2 / 3$ não ultrapassem, hoje, os $1905 €$. Se ultrapassarem, o trabalhador recebe menos do que esses $2 / 3$, recebe $1905 €$.

Ora, no contexto da pandemia que enfrentamos, o Governo, através do DL no 10-G/2020, de 26 de março, alterado pela Declaração de Retificação no 14/2020, de 28 de março, veio estabelecer um conjunto de medidas excecionais e temporárias, definindo e regulamentando os termos e as condições de atribuição dos apoios destinados aos trabalhadores e às empresas afetados pela pandemia da COVID-19 tendo em vista a manutenção dos postos de trabalho e a mitigação de situações de crise empresarial. Este diploma legal foi complementado pelo DL no 12-A/2020, de 6 de abril, estendendo também a possibilidade de lay-off nos termos do art. 26으 para os trabalhadores independentes, criando uma forma de lay-off simplificado.

As medidas excecionais previstas no diploma aplicam-se aos empregadores de natureza privada e aos trabalhadores ao seu serviço, afetados pela pandemia da COVID-19 e que se encontrem, em consequência, em situação de crise empresarial, mediante requerimento eletrónico apresentado pela entidade empregadora junto dos serviços da Segurança Social. A situação de crise empresarial, pressuposto de aplicação destas medidas, encontra-se definida no art. 3o-, compreendendo, designadamente: i) o encerramento total ou parcial da empresa ou estabelecimento, decorrente do dever de encerramento de instalaçóes e estabelecimentos; ii) a paragem total ou parcial da atividade da empresa ou estabelecimento que resulte da interrupção das cadeias de 
abastecimento globais, ou da suspensão ou cancelamento de encomendas, que possam ser documentalmente comprovadas (pode tratar-se de uma paragem de atividade ainda não registada, mas tornada inevitável, em função do cancelamento de encomendas ou de reservas, dos quais resulte que a utilização da empresa ou da unidade afetada será reduzida em mais de $40 \%$ da sua capacidade de produção ou de ocupação no mês seguinte ao do pedido de apoio); iii) a quebra abrupta e acentuada de, pelo menos, $40 \%$ da faturação no período de trinta dias anterior ao do pedido junto dos serviços competentes da segurança social, com referência à média mensal dos dois meses anteriores a esse período, ou face ao período homólogo do ano anterior ou, ainda, para quem tenha iniciado a atividade há menos de 12 meses, à média desse período.

Em tais situações de crise empresarial, o empregador poderá reduzir temporariamente os períodos normais de trabalho ou suspender os contratos de trabalho, sendo aplicável, com as necessárias adaptaçôes, o disposto no CT. A compensação retributiva a que o trabalhador tem direito é a prevista no no 3 do art. 305o do CT, sendo paga pelo empregador. No período de aplicação desta medida, a empresa tem direito a um apoio financeiro para efeitos de pagamento da referida compensação retributiva, nos termos do no 4 do art. 305o do CT - apoio equivalente a 70\% do respetivo montante.

Norma bastante importante deste Diploma legal é a que se encontra no art. 13o com a epígrafe Proibição do despedimento, e onde se lê que "Durante o período de aplicação das medidas de apoio previstas no presente decreto-lei, bem como nos 60 dias seguintes, o empregador abrangido por aquelas medidas não pode fazer cessar contratos de trabalho ao abrigo das modalidades de despedimento coletivo ou despedimento por extinção do posto de trabalho, previstos nos artigos 359o e 3670 do Código do Trabalho”. E o art. 14ำ, no 1, alínea a) estabelece que o incumprimento, por parte do empregador, das obrigaçóes relativas aos apoios previstos na lei, implica a imediata cessação dos mesmos e a restituição dos montantes já recebidos, quando se verifique, entre outras situações, a de "despedimento, exceto por facto imputável ao trabalhador".

Contudo, como bem realça João Leal $\mathrm{Amado}^{7}$, a lei não é muito clara nalguns aspetos e origina algumas dúvidas de interpretação, assim como no que concerne ao

7 “Da pandemia ao “lay-off simplificado": breve reflexão", in RLJ, no 4021, pp. 250 e ss.. 
âmbito de proteção que confere aos trabalhadores. Assim, parece óbvio que a lei não impede as empresas que beneficiem desses apoios públicos extraordinários de lançar no desemprego os trabalhadores com vínculos precários, fazendo, inter alia, caducar os contratos a termo ou de trabalho temporário, ou denunciando os contratos durante o período experimental. A lei proíbe, apenas, o recurso ao despedimento coletivo ou por extinção de posto de trabalho.

Contudo, creio que também proíbe o despedimento por inadaptação ${ }^{8}$, visto que este não se traduz num despedimento por justa causa, disciplinar, por facto imputável ao trabalhador, única modalidade de despedimento autorizada, segundo resulta do art. 14o. Por outro lado, a proibição de despedimento aparece balizada no tempo - durante o período de aplicação das medidas de apoio previstas no diploma, bem como nos 60 dias seguintes -, pelo que mais tarde, esgotados que sejam esses 60 dias, nada impedirá a entidade empregadora de recorrer a esses mecanismos extintivos da relação laboral, se entender que tal se justifica.

Restam ainda dúvidas sobre a situação de entidades empregadoras que, antes de recorrerem a tais medidas de apoio público, tenham procedido ao despedimento ilícito de trabalhadores como, por exemplo, sem respeitar os procedimentos, sem conceder pré-aviso, sem pagar as devidas compensações. Nestas situações concorda-se inteiramente com o defendido por João Leal Amado", ao escrever que "competindo às entidades públicas fiscalizar, a posteriori, as empresas beneficiárias dos apoios extraordinários, a comprovação de que tais despedimentos patentemente ilícitos terão ocorrido em plena crise pandémica, ainda que antes do requerimento de tais medidas de apoio extraordinário, deveria implicar a aplicação das consequências previstas no art. 14º em sede de incumprimento e restituição do apoio concedido. Se assim não for, os empregadores menos escrupulosos, aqueles que, logo no dealbar da crise, não hesitaram em

8 Veja-se Cristina Martins da Cruz, "O "Lay off” no contexto da «pandemia COVID-19»", in Estado de emergência - COVID-19-implicações na justiça, CEJ, 2020: 597 e João Leal Amado, "Da pandemia ao "lay-off simplificado"..., cit..

$9 \mathrm{Da}$ pandemia ao lay-off just in time: breve reflexão, in https://observatorio.almedina.net/index. php/2020/03/30/da-pandemia-ao-lay-off-just-in-time-breve-reflexao/. 
abandonar os seus "colaboradores", ainda que ilegalmente, acabarão, quiçá, por ser beneficiados pela sua presteza e total falta de "responsabilidade social". Não pode ser".

Mais, a violação deste artigo, tal como nota João Leal Amado ${ }^{10}$ não parece tornar o despedimento ilícito no sentido estabelecido nos arts. 381o e ss. do CT, tendo apenas consequências em sede de perda de apoios concedidos, ou seja, de restituição ou pagamento pelo empregador, conforme o caso, ao Instituto da Segurança Social e ao Instituto do Emprego e Formação Profissional, dos montantes já recebidos ou isentados nos termos do art. $14^{\circ}$, assim como em sede de responsabilidade contraordenacional da

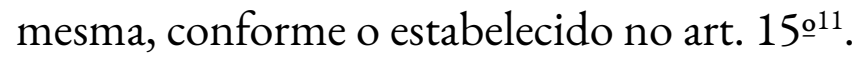

7 Tendo isto em atenção saúda-se vivamente uma outra medida que foi adotada pelo Governo no Decreto no 2-B/2020, de 2 de abril, que veio regulamentar a prorrogação do estado de emergência decretado pelo Presidente da República, através do art. 24o, com a epígrafe Reforço dos meios e poderes da Autoridade para as Condiçóes do Trabalho (ACT), o qual dispóe o seguinte, nos dois primeiros números:

“ 1 - Durante a vigência do presente decreto e de forma a reforçar os direitos e garantias dos trabalhadores, sempre que inspetor do trabalho verifique a existência de indícios de um despedimento em violação dos artigos 381으, 382, 383o ou 384o do Código do Trabalho, aprovado pela Lei no 7/2009, de 12 de fevereiro, na sua redação atual, lavra um auto e notifica o empregador para regularizar a situação.

10 Da pandemia ao "lay-off simplificado"..., cit..

11 Convém ter em atenção que no Programa de Estabilização Económica e Social, aprovado pela Resolução do Conselho de Ministros no 41/2020, de 6 de junho, no ponto 2.2. fica a saber-se que o lay-off simplificado abrangeu cerca de 100000 empresas e 800000 trabalhadores, sendo que este modelo é prorrogado até finais de julho deste ano, sendo que após esta data, as empresas que tenham beneficiado do regime de lay -off simplificado como uma forma de apoio à retoma económica, podem passar a beneficiar de um incentivo extraordinário à normalização da atividade empresarial, escolhendo uma de duas modalidades: "1 SMN one-off ou 2 SMN ao longo de 6 meses, com condicionalidades no que diz respeito à proibição de despedimentos e de extinção de postos de trabalho". Contudo, mais uma vez, há requisitos, e quanto a nós muito bem, e as empresas que recorram a estas medidas não podem proceder a despedimentos coletivos, por extinção do posto de trabalho e por inadaptação durante a aplicação da medida e nos 60 dias subsequentes, assim como também ficam proibidas de distribuir dividendos durante a aplicação da medida. 
2 - Com a notificação ao empregador nos termos do número anterior e até à regularização da situação do trabalhador ou ao trânsito em julgado da decisão judicial, conforme os casos, o contrato de trabalho em causa não cessa, mantendo-se todos os direitos das partes, nomeadamente o direito à retribuição, bem como as inerentes obrigaçôes perante o regime geral de segurança social”.

O Decreto no 2-B/2020, de 2 de abril, veio a ser revogado e substituído pelo Decreto no 2-C/2020, de 17 de abril, diploma que reproduziu, ipsis verbis, a norma, nos dois primeiros números do art. 26o. Entretanto, o estado de emergência terminou e passamos, juridicamente, para uma situação de calamidade. E esta norma manteve-se nos termos do novo art. 8--C da Lei no 1-A/2020, de 19 de março, aditado pela Lei no 14/2020, de 9 de maio.

Claro que se tem perfeita consciência de que não é uma norma isenta de críticas, algumas até sobre a constitucionalidade da mesma feitas já pela Ordem dos Advogados, assim como dificuldades de interpretação e até de aplicação. Contudo, apesar destas críticas, parece-nos ser uma medida de aplaudir. Vivemos tempos novos, em que é difícil legislar, em que é necessário legislar quase diariamente consoante o decurso das circunstâncias como já referimos, pelo que esta norma, apesar das suas dificuldades, nos parece positiva. Convém, contudo, atender à sua especificidade.

Esta norma não proíbe os despedimentos. O empregador continua a poder despedir nos termos previstos no CT, a não ser se tiver recorrido ao regime do lay-off simplificado e nas situaçôes já proibidas e referidas anteriormente.

O que se pretendeu com esta norma parece-nos é dar um procedimento mais célere no caso dos despedimentos ilícitos. Para esse efeito, a norma concede um novo poder à $\mathrm{ACT}$ que é o de, sempre que um inspetor do trabalho verificar a existência de indícios de um despedimento ilícito, lavrar um auto e notificar o empregador para regularizar a situação. Essa notificação terá, então, o efeito de suspender a eficácia da decisão de despedimento, mantendo-se o contrato de trabalho em vigor até que a situação seja regularizada ou até ao trânsito em julgado da decisão judicial. Com esta notificação, o despedimento fica suspenso, ou seja, a eficácia extintiva da declaração de despedimento é paralisada, pelo que o contrato de trabalho retoma a sua vigência. E isto parece-nos claramente positivo. 
Assim, analisando esta norma, secunda-se inteiramente o escrito por João Leal Amado $^{12}$ :

"Numa situação de emergência nacional, de calamidade, de pandemia, em que, como se tem dito, ninguém deve ser deixado para trás, a lei não é radical, não pró́be que o empregador despeça, nem sequer altera os termos e as condições em que o empregador pode despedir. Os fundamentos a invocar e os procedimentos a adotar continuam a ser os já antes previstos no CT. Mas a lei tenta evitar que o empregador, neste contexto de crise, despeça ilicitamente, depositando na ACT o poder de paralisar, ainda que transitoriamente, os efeitos de um despedimento que revele fortes indícios de ilicitude".

Esta é uma medida de urgência para uma situação de emergência. É uma medida, "pouco ortodoxa" 13 , mas que tem a vantagem de permitir suspender despedimentos com fortes indícios de ilegalidade sem forçar o trabalhador despedido a reagir judicialmente, pelo menos num primeiro momento pois pode denunciar o caso à $\mathrm{ACT}$ e será o inspetor do trabalho que, depois de analisar a situação, ainda que superficialmente, poderá lavrar o auto e notificar o empregador. Para além disso, convém não esquecer, é uma medida provisória na medida em que tudo irá depender da atuação do empregador notificado que pode regularizar a situação se assim quiser, ou da decisão judicial que vier a ser proferida. Parece-nos ser uma medida cautelar que se justifica inteiramente atenta a necessidade de não pactuar com práticas de empregadores que violem claramente a lei.

8 Relativamente às férias o legislador não adotou especiais medidas nesta altura a não ser na parte relativa à marcação das mesmas, previsto no art. 241o do CT. O art. 240 do CT estabelece que as férias são gozadas, em princípio, no ano em que se vencem e, nos termos do art. 241 do CT, serão marcadas por acordo entre as partes, ou, na inexistência de acordo, pelo empregador, o qual, porém, nesta hipótese de marcação unilateral, tem de obedecer às regras previstas neste preceito. Em caso algum, porém,

12 "Emergência, calamidade e despedimento...", cit.

13 João Leal Amado, última op. cit. 
admite-se que seja o trabalhador a decidir, sem acordo do empregador, em que momento gozará as mesmas.

Ora, a título excecional, o art. 2o, nos 5 e 6 do Decreto-Lei no 10-K/2020, de 26 de março, que estabelece um regime excecional e temporário de faltas justificadas motivadas por assistência à familia, no âmbito da pandemia da doença COVID-19, prescreve que:

"Para prestar assistência nas situaçôes previstas nas alíneas a) e b) do no 1, o trabalhador pode proceder à marcação de férias, sem necessidade de acordo com $\mathrm{o}$ empregador, mediante comunicação, por escrito com antecedência de dois dias relativamente ao início do período de férias.

6 - Durante o período de férias previsto no número anterior é devida retribuição do período correspondente à que o trabalhador receberia se estivesse em serviço efetivo, não se aplicando o no 3 do artigo 264o do Código do Trabalho, podendo neste caso o subsídio de férias ser pago na sua totalidade até ao quarto mês seguinte ao do início do gozo de férias”.

Contudo, esta possibilidade não se aplica aos profissionais de saúde, das forças e serviços de segurança e de socorro, incluindo os bombeiros voluntários, e das forças armadas, os trabalhadores dos serviços públicos essenciais, de gestão e manutenção de infraestruturas essenciais, bem como outros serviços essenciais.

Por outro lado, o legislador estabeleceu no art. 32--A, do DL no 12-A/2020, de 6 de abril que "a aprovação e afixação do mapa de férias até ao dia 15 de abril, nos termos do no 9 do artigo 241ㅇ do Código do Trabalho, aprovado pela Lei no 7/2009, de 12 de fevereiro, na sua redação atual, e por remissão da alínea i) do ㄲo 1 do artigo 4o , do ㄲo 1 do artigo 122o e do artigo 126o da Lei Geral do Trabalho em Funçóes Públicas, aprovada em anexo à Lei no 35/2014, de 20 de junho, na sua redação atual, respetivamente, pode ter lugar até 10 dias após o termo do estado de emergência”.

9 No âmbito desta pandemia coloca-se também a questão da realização de medição de temperatura dos trabalhadores pelo empregador como uma forma de tentar diminuir o contágio entre pessoas. 
Os dados obtidos com esta medição são dados sensiveis, ou categorias especiais de dados pessoais ao abrigo do art. 9o do Regulamento Geral de Proteção de Dados Pessoais (RGPD). A regra geral no que concerne este tratamento é a de que não podem ser tratados, a não ser ou com o consentimento do titular dos dados que, neste caso da relação de trabalho, não parece relevar.

$\mathrm{Na}$ verdade, o RGPD retirou o acento tónico do consentimento como fundamento jurídico válido para o tratamento de dados pessoais quando, nos termos do considerando 43, "exista um desequilíbrio manifesto entre o titular dos dados e o responsável pelo seu tratamento", como é o caso, claramente, da relação de trabalho. Este considerando é muito importante porque significa que para que um tratamento de dados pessoais realizado pelo empregador seja válido terá de assentar noutros princípios que não o mero consentimento do trabalhador. E esta ideia é reforçada quer pela redação do próprio art. 4º ao definir que o consentimento do titular dos dados é "uma manifestação de vontade, livre, específica, informada e explícita, pela qual o titular dos dados aceita, mediante declaração ou ato positivo inequívoco, que os dados pessoais que lhe dizem respeito sejam objeto de tratamento", quer pelo próprio art. 7o, sobretudo os números 1 e 4, que estabelecem, respetivamente, que "quando o tratamento for realizado com base no consentimento, o responsável pelo tratamento deve poder demonstrar que o titular dos dados deu o seu consentimento para o tratamento dos seus dados pessoais", e que "ao avaliar se o consentimento é dado livremente, há que verificar com a máxima atenção se, designadamente, a execução de um contrato, inclusive a prestação de um serviço, está subordinada ao consentimento para o tratamento de dados pessoais que não é necessário para a execução desse contrato”.

Parece-nos, sem dúvida, que a noção de consentimento, entendido como uma manifestação de vontade livre, específica e informada, é um conceito de difícil concretização e de difícil preenchimento no contexto de uma relação de trabalho.

Considera-se que, no âmbito laboral, o requisito do consentimento fica relegado para um segundo plano já que o trabalhador interessado se encontra numa posição de desigualdade em relação ao responsável pelo tratamento, isto é, o empregador, desigualdade na sua necessidade de obtenção de um posto de trabalho, no caso dos candidatos a emprego, ou de manutenção do mesmo, no caso de trabalhadores. Não 
parece que neste tipo de relação se possa falar de um consentimento prestado livremente, principalmente quando o consentimento é requisito para a obtenção de um serviço essencial ou, no caso que aqui nos interessa, para a manutenção de um posto de trabalho, não podendo falar-se aqui de uma verdadeira liberdade de escolha.

Quando uma das partes está submetida ao poder contratual de outrem, não usufruindo de suficiente margem de defesa dos seus próprios interesses e de autoafirmação, o seu consentimento em relação ao contrato e aos vários termos deste não confere qualquer garantia substancial de integrar uma manifestação verdadeira de autodeterminação.

Contudo, não pode deixar de ter-se em atenção que na relação laboral torna-se necessária a recolha de numerosas informações dos trabalhadores para a correta execução do contrato de trabalho, sendo, assim, este tratamento uma consequência quase natural deste tipo de relaçóes. Atendendo a tudo isto, defende-se uma inevitável evolução no sentido de colocar o pressuposto legitimador do tratamento de dados pessoais não no consentimento individual do trabalhador, mas na ampliação do número de pressupostos alternativos a este consentimento. Entende-se que deve assumir importância a técnica de tipo objetivo, isto é, que assente a legitimidade do tratamento no respeito pelo princípio da finalidade e no prosseguimento de fins específicos e não de outros, colocando o acento tónico neste princípio e na ideia do tratamento ser pertinente e necessário, respeitando sempre o princípio da proporcionalidade.

Esta construção parece-nos trazer uma maior dose de garantia do ponto de vista laboral, já que, ainda que o consentimento do trabalhador tenha sido prestado, se o tratamento não respeitar estes princípios, isto é, se não for pertinente, nem necessário, ou não tiver uma finalidade lícita, será sempre ilícito. O carácter irrenunciável dos direitos de personalidade a isso obsta ${ }^{14}$.

14 Para maiores desenvolvimentos vide Teresa Coelho Moreira (2020). Algumas questóes sobre o Regulamento Geral de Proteção de dados e as relações de trabalho, in O Regulamento Geral de Proteção de Dados $e$ as Relaçôes de Trabalho, Estudos APODIT, volume VI (coordenação Maria do Rosário Palma Ramalho e Teresa Coelho Moreira), Lisboa, AAFDL: 15 e ss., assim como Dados Pessoais: breve análise do art. 28o da lei no 58/2019, de 8 de agosto, in $Q L$, no 55: 41 e ss., e (2018).A proteção de dados pessoais dos trabalhadores em Portugal, in 4a Revolución Industrial: Impacto de la Automatización y la Inteligencia Artificial en la Sociedad y la Economia Digital, Espanha, Thomson Reuters, Aranzadi. 
Outra situação em que é possível o tratamento é se "for necessário para efeitos do cumprimento de obrigações e do exercício de direitos específicos do responsável pelo tratamento ou do titular dos dados em matéria de legislação laboral, de segurança social e de proteção social, na medida em que esse tratamento seja permitido pelo direito da União ou dos Estados-Membros ou ainda por uma convenção coletiva nos termos do direito dos Estados-Membros que preveja garantias adequadas dos direitos fundamentais e dos interesses do titular dos dados"15, ou ainda, e parece-nos ser este o caso nestas situaçóes, "Se o tratamento for necessário para efeitos de medicina preventiva ou do trabalho, para a avaliação da capacidade de trabalho do empregado, o diagnóstico médico, a prestação de cuidados ou tratamentos de saúde ou de ação social ou a gestão de sistemas e serviços de saúde ou de ação social com base no direito da União ou dos Estados-Membros ou por força de um contrato com um profissional de saúde, sob reserva das condiçóes e garantias previstas no no 3 ”16. E estas garantias estabelecem que "Os dados pessoais referidos no no 1 podem ser tratados para os fins referidos no no 2, alínea h), se os dados forem tratados por ou sob a responsabilidade de um profissional sujeito à obrigação de sigilo profissional ${ }^{17}$, nos termos do direito da União ou dos Estados-Membros ou de regulamentação estabelecida pelas autoridades nacionais competentes, ou por outra pessoa igualmente sujeita a uma obrigação de confidencialidade ao abrigo do direito da União ou dos Estados-Membros ou de regulamentação estabelecida pelas autoridades nacionais competentes”.

Assim, parece-nos claramente possível a realização de testes aos trabalhadores e, por isso, concorda-se com o que está previsto no art. 13o - C, com a epígrafe Controlo de temperatura corporal, do DL no 20/2020, de 1 de maio, mantido exatamente nos mesmos termos pelo DL no 22/2020, de 16 de maio. Neste artigo estabelece-se:

"1 - No atual contexto da doença COVID-19, e exclusivamente por motivos de proteção da saúde do próprio e de terceiros, podem ser realizadas medições de temperatura corporal a trabalhadores para efeitos de acesso e permanência no local de trabalho.

15 Art. 9o, no 2, alínea b) do RGPD.

16 Art. 9o, no 2, alínea h) do RGPD.

17 Negrito nosso. 
2 - O disposto no número anterior não prejudica o direito à proteção individual de dados, sendo expressamente proibido o registo da temperatura corporal associado à identidade da pessoa, salvo com expressa autorização da mesma.

3 - Caso haja medições de temperatura superiores à normal temperatura corporal, pode ser impedido o acesso dessa pessoa ao local de trabalho”.

Ora, atendendo ao disposto nesta norma, realizado no âmbito de uma situação excecional, conforme referido no preâmbulo do diploma legal, no "âmbito da emergência de saúde pública de âmbito internacional causada pela doença COVID-19”, justifica-se a necessidade de medir a temperatura corporal dos trabalhadores, já que se sabe que um dos possíveis sintomas da existência deste vírus é febre.

O empregador, dentro dos seus deveres fundamentais, tem o dever de proporcionar boas condições de trabalho, protegendo a segurança e saúde do trabalhador. Este, por seu lado, também tem de respeitar as regras sobre segurança e saúde no trabalho.

Tendo em atenção este quadro normativo, defende-se a possibilidade de realização deste controlo. Assim, a questão que se coloca é sobre como e de que forma pode ser realizado o mesmo. E aqui parece-nos fundamental lembrar o previsto no RGPD, mas também o previsto no art. 19 do CT, que estabelece, sob a epígrafe Testes e exames médicos, que:

"1 - Para além das situações previstas em legislação relativa a segurança e saúde no trabalho, o empregador não pode, para efeitos de admissão ou permanência no emprego, exigir a candidato a emprego ou a trabalhador a realização ou apresentação de testes ou exames médicos, de qualquer natureza, para comprovação das condiçóes físicas ou psíquicas, salvo quando estes tenham por finalidade a proteção e segurança do trabalhador ou de terceiros, ou quando particulares exigências inerentes à atividade o justifiquem, devendo em qualquer caso ser fornecida por escrito ao candidato a emprego ou trabalhador a respetiva fundamentação.

2 - O empregador não pode, em circunstância alguma, exigir a candidata a emprego ou a trabalhadora a realização ou apresentação de testes ou exames de gravidez. 3 - O médico responsável pelos testes e exames médicos só pode comunicar ao empregador se o trabalhador está ou não apto para desempenhar a atividade $^{18}$.

18 Negrito nosso. 
4- Constitui contraordenação muito grave a violação do disposto nos nos 1 ou 2.”

Assim, quando no no 2 do art. 13--C do DL no 20/2020, de 1 de maio, estabelece que "O disposto no número anterior não prejudica o direito à proteção individual de dados, sendo expressamente proibido o registo da temperatura corporal associado à identidade da pessoa, salvo com expressa autorização da mesma”, parece-nos que quando o legislador se refere a não prejudicar o direito à proteção individual de dados, tem de ser interpretado no sentido de que apenas os profissionais de saúde ou sob a responsabilidade deste, e sujeitos ao sigilo profissional, poderão realizar esta medição.

Repete-se, não é proibida a medição da temperatura. A questão está na forma como será efetuada e, sobretudo, por quem será efetuada.

Atendendo a estes considerandos, o tratamento de dados de saúde pode ser realizado, mas respeitando os princípios de proteção de dados pessoais, ou seja, desde logo o princípio da finalidade legítima que está assegurado no no 1 do art. 13--C, o princípio da proporcionalidade, sendo realizado pelas autoridades habilitadas ou sob a responsabilidade delas, e sujeitas ao sigilo profissional, e o princípio da transparência, pois têm de existir regras concretas sobre esta matéria.

Mas este artigo não deixa de suscitar-nos várias dúvidas. Assim, e desde logo, qual é a temperatura corporal normal? 37 graus? 37,5 ? $38^{19}$ ? No ordenamento jurídico italiano estabeleceu-se 37,5 graus, mas em Portugal não há qualquer referência.

Por outro lado, a temperatura corporal pode variar consoante a hora, o local onde é feita a medição e mesmo o aparelho que é utilizado. E qual o aparelho deve ser este? Também não há qualquer referência. Por outro lado, se o trabalhador apresentar uma temperatura corporal acima da média pode ser impedido de aceder ao local de trabalho. Ora, neste caso, qual a consequência para o trabalhador? Não parece existir aqui uma falta no conceito legal, pois o trabalhador apresenta-se no local e

19 No Guia da DGS sobre Saúde e Trabalho - medidas de prevenção da COVID-19 nas empresas, de 28 de abril de 2020: 13, 2.5., estabelece-se como temperatura suspeita igual ou superior a 38 graus, assim como a tosse persistente, ou agravamento da tosse habitual, e a dispneia/dificuldade respiratória como os sintomas comuns da COVID-19. Atendendo a isto parece-nos que só deverá ser considerada uma "temperatura superior à normal" a que for igual ou superior a 38 . 
no tempo de trabalho para trabalhar. Há é, sim, uma ausência ordenada pela entidade empregadora, que terá de ser suportada pela mesma. E por quanto tempo? Terá o empregador de pagar estas ausências até o trabalhador saber o resultado dos testes médicos para saber se é ou não portador do vírus SARS-CoV-2 e da doença COVID-19?

O trabalhador que é impedido de trabalhar tem a obrigação de entrar em contacto com as entidades competentes para ir realizar um teste de deteção? Parece-nos que a resposta terá de ser afirmativa, atendendo ao dever geral que incumbe a todos os cidadãos e, neste caso particular, ao trabalhador, que também tem de cumprir com as regras de segurança e saúde no trabalho.

Assim, conclui-se, defendendo que é possível a realização da medição da temperatura corporal dos trabalhadores, mas com regras que respeitem sempre a proteção de dados pessoais. Na prática, as questóes surgem, precisamente, na forma de conciliar a resposta positiva do legislador quanto à possibilidade de medição de temperatura corporal dos trabalhadores com a devida proteção dos seus dados pessoais, não esquecendo que a temperatura fora do normal pode dever-se a múltiplos fatores que nada estão relacionados com a COVID. Será que não estaremos perante a quadratura do círculo?20

\section{CONCLUSÃO}

Perante esta situação de crise convém recordar que a crise económica é "uma realidade que tem acompanhado o Direito do Trabalho, pelo menos de forma intermitente, ao longo do seu percurso histórico, para converter-se, certamente, num «companheiro de viagem histórico» da mesma, incómodo se se quiser»"21. Contudo, não pode deixar de ter-se em atenção que esta é uma crise sem precedentes pois é uma crise sanitária, económica, verdadeiramente mundial, que vai colocar desafios sem precedentes ao Direito do trabalho.

\footnotetext{
20 Para maiores desenvolvimentos veja-se Teresa Coelho Moreira, O controlo da temperatura dos trabalhadores no âmbito do COVID-19, in https://observatorio.almedina.net/index.php/2020/05/05/o-controlo-da-temperatura-dos-trabalhadores-no-ambito-do-COVID-19/.

21 Palomeque López (2001). Direito do Trabalho e Ideologia, (trad. Anatónio Moreira), Coimbra, Almedina: 39.
} 
Porém, perante esta situação consideramos que o Direito do trabalho tem uma sólida e provada experiência de maleabilidade e que irá adaptar-se e superar esta situação.

Braga, 8 de junho de 2020 